\title{
As residências terapêuticas e a clínica do cotidiano: contribuições da terapia ocupacional
}

\section{Therapeutic residences and everyday life clinic: occupational therapy contributions}

\author{
Sabrina Helena Ferigato1, Maria Luisa Gazabin Simões Ballarin², Taís Quevedo \\ Marcolino $^{3}$, Sandrina Kelen Indiani ${ }^{4}$
}

http://dx.doi.org/10.11606/issn.2238-6149.v27i1p80-87

Ferigato SH, Ballarim MLG, Marcolino TQ, Indiani SK. As residências terapêuticas e a clínica do cotidiano: contribuições da terapia ocupacional. Rev Ter Ocup Univ São Paulo. 2016 jan.-abr.;27(1):80-7.

RESUMO: O objeto desse relato de experiência é a atuação da Terapia Ocupacional junto às Residências Terapêuticas. Temos como objetivo a sistematização dessa atuação a partir da descrição e análise do trabalho de terapeutas ocupacionais nestes serviços. Para isso, partimos da valorização da dimensão da experiência de terapeutas ocupacionais vinculados a Serviços Residenciais Terapêuticos e a aproximação de seus registros. Esses registros foram construídos como diários de campo e posteriormente analisados. Para a análise de dados utilizamos o método de avaliação de diários de campo, proposto por Lourau, partindo do referencial teórico da Clínica Psicossocial, da Análise Institucional e referencias do cotidiano propostos na Terapia Ocupacional. Como resultados, apresentaremos a sistematização da atuação da terapia ocupacional em serviços residenciais a partir de 4 planos: (1) intervenções na casa; (2) intervenções junto aos moradores; (3) ações no território e na comunidade; (4) ações junto à equipe de trabalho e à rede intersetorial. Esses planos, quando articulados na discussão e considerações finais, apontam para a potência que as especificidades do núcleo da terapia ocupacional podem trazer para as ações realizadas nos serviços residenciais terapêuticos, especialmente no se refere à abordagem psicossocial com ênfase no cotidiano e nos processos de desisntitucionalização.

DESCRITORES: Serviços de assistência domiciliar; Terapia ocupacional; Desinstitucionalização; Atividades cotidianas.
Ferigato SH, Ballarim MLG, Marcolino TQ, Indiani SK. Therapeutic residences and everyday life clinic: occupational therapy contributions. Rev Ter Ocup Univ São Paulo. 2016 Jan.-Apr.;27(1):80-7.

\begin{abstract}
The purpose of this experience report is the practice of the Occupational Therapy at the Therapeutic Residences. We aim to systematize this practice from the description and analysis of the work of occupational therapists in these services. For this, we start from the appreciation of the experience level of occupational therapists linked to Therapeutic Residential Services and the approximation of their records. These records were written as field journal and later analyzed. For data analysis, we used the field journal evaluation method proposed by Lourau, starting from the theoretical framework of the Psychosocial Clinic, Institutional Analysis and everyday life references proposed in the Occupational Therapy. As a result, we will present the systematization of the practice of the occupational therapy in residential services from 4 plans: (1) interventions at home; (2) interventions with residents; (3) actions in the territory and in the community; (4) actions with the work team and the intersectoral network. These plans, when interrelated in the discussion and final remarks, point out the power that the particularities of the occupational therapy center can bring to the actions developed in the residential therapeutic services, especially regarding the psychosocial approach with emphasis on everyday life and deinstitutionalization processes.
\end{abstract}

KEYWORDS: Home care services; Occupational therapy; Deinstitutionalization; Activities of daily living.

1. Universidade Federal de São Carlos (UFSCar). Departamento de Terapia Ocupacional. Email: sabrinaferigato@gmail.com.

2. Pontifícia Universidade Católica de Campinas (PUCCamp). Faculdade de Terapia Ocupacional. Email: awballarin@uol.com.br

3. Universidade Federal de São Carlos (UFSCar). Departamento de Terapia Ocupacional. EMail: taisquevedo@gmail.com

4. Serviço de Saúde Dr. Cândido Ferreira. Email: san.indiani@gmail.com

Endereço para correspondência: Departamento de Terapia Ocupacional - UFSCar. Rodovia Washington Luís, s/n - Jardim Guanabara, São Carlos - SP, 13565-905. 
Ferigato SH, et al. As residências terapêuticas e a clínica do cotidiano. Rev Ter Ocup Univ São Paulo.2016 jan./abr.;27(1):80-7.

\section{INTRODUÇÃO}

$\mathrm{E}$ sse manuscrito pretende discutir as ações desenvolvidas por terapeutas ocupacionais nas Residências Terapêuticas (RT) ou Serviços Residenciais Terapêuticos (SRT), utilizando os referenciais teóricos da Clínica Psicossocial, Análise Institucional e do Cotidiano na Terapia Ocupacional no contexto da reforma Psiquiátrica.

Neste contexto, é importante abordarmos os equipamentos substitutivos que buscam consolidar um novo modo de atenção à saúde, como os Centros de Atenção Psicossocial (CAPS), os Centros de Convivência, as Oficinas de Geração de Renda, as Enfermarias de Saúde Mental em Hospital Geral e as Residências Terapêuticas.

Para Yasui ${ }^{1}$, a Reforma Psiquiátrica é um processo civilizador, um processo social complexo que produziu profundas rupturas com modelos hegemônicos de cuidado, além de novos paradigmas na relação com a loucura, seja no campo epistemológico, técnico-assistencial, jurídicopolítico e sociocultural. O processo de desistitucionalização dos internos de hospitais psiquiátricos foi um de seus grandes desafios, que continua presente ente até os dias atuais.

Nesse contexto, as Residências Terapêuticas foram e são estratégias fundamentais para reduzir leitos de longa permanência e superar a condição cronificante de moradores de hospitais psiquiátricos, seja pelo suporte que esse dispositivo oferece para garantir sua permanência fora do hospital, seja pela dificuldade encontrada nas tentativas de reinserção familiar de parte dos usuários institucionalizados ${ }^{2}$. Essa estratégia foi reafirmada pela coordenação da Política Nacional de Saúde Mental na ocasião de constituição da Rede de Atenção Psicossocial (RAPS), instituída de acordo com a portaria $\mathrm{GM} / \mathrm{MS} \mathrm{n}^{\circ} 3.088 / 2011$.

A RAPS, para além de um modelo assistencial, adensa um novo cenário político-institucional da saúde que pretende se fortalecer por meio da constituição e fortalecimento das redes de atenção integrais. Pautado nos princípios da Reforma Psiquiátrica, inclui práticas e saberes de afirmação dos direitos humanos, da garantia de liberdade e autonomia, o exercício da cidadania, da equidade e da inclusão social; visando consolidar práticas substitutivas ao modelo asilar.

Um dos principais componentes da RAPS são as Estratégias de desinstitucionalização,

constituídas por iniciativas que visam a garantir às pessoas com transtorno mental [...] em situação de internação de longa permanência, o cuidado integral por meio de estratégias substitutivas, na perspectiva da garantia de direitos com a promoção de autonomia e o exercício de cidadania ( p.11) ${ }^{3}$.

Atualmente, as Residências Terapêuticas, junto com o Programa de Volta para Casa, constituem-se como as principais "estratégias de desinstitucionalização" que compõem a Rede de Atenção Psicossocial brasileira.

Mesmo antes desse equipamento integrar formalmente o SUS pela Portaria/GM de $\mathrm{n}^{\mathrm{o}} 106 \mathrm{em}$ 2000, algumas experiências de moradias para pessoas com transtornos mentais já haviam sido descritas desde o final da década de oitenta. Tais moradias foram implantadas em casas independentes, inicialmente denominadas de lares abrigados, pensões protegidas ou moradias assistidas ${ }^{4,5}$.

Ao longo de três décadas, esse equipamento passou por transformações em relação à sua relevância e abrangência ${ }^{6}$. Em 2011, eram mais de 4000 moradores inseridos em 625 Residências existentes em todo território nacional ${ }^{3}$.

A expansão dos CAPS, a desativação de leitos psiquiátricos e alocação de recursos financeiros federais em estratégias comunitárias figuram como fatores relevantes na expansão da rede de RT em todo território nacional ${ }^{3}$.

De acordo com o Ministério da Saúde podemos definir os as residências terapêuticas como "casas localizadas no espaço urbano, constituídas para responder às necessidades de moradia, apresentadas por pessoas portadoras de transtornos mentais graves, institucionalizadas ou não" (s.n) ${ }^{7}$.

Mas, se uma Residência Terapêutica é um dispositivo produzido para acolher as necessidades de moradia de pessoas com transtornos mentais que não possuem outras possibilidades de habitar um lar, de que se trata exatamente trabalhar com a apropriação do espaço residencial como moradia? Como podemos contribuir para a efetivação desse processo?

Diante de questões como estas e da experiência vivida por terapeutas ocupacionais, membros de uma equipe interdisciplinar em um CAPS III na cidade de Campinas/SP, buscamos sistematizar as ações em terapia ocupacional realizadas nesse processo. Compreendemos que, embora se trate de uma experiência local, os aspectos aqui trabalhados são passíveis de aplicação em outros dispositivos como esse no contexto nacional.

Entendemos a importância da construção interdisciplinar dos processos de cuidado realizados nesses dispositivos, pois afirmamos que este não é um legado de nenhum núcleo disciplinar, mas sim uma abordagem 
constituinte do campo da Saúde Mental. Entretanto, como se trata de um cuidado extremamente próximo do núcleo da terapia ocupacional, por abordar uma clínica que se constrói em um espaço privilegiado de construção do cotidiano, buscaremos refletir sobre a construção do trabalho desta profissão nesse equipamento e vislumbrar contribuições ao campo da saúde mental, decorrentes do que nos é específico.

\section{REFLEXÕES SOBRE O MORAR, O COTIDIANO E A TERAPIA OCUPACIONAL}

O conceito de cotidiano tem sido historicamente discutido por diversas disciplinas, como as Ciências Sociais, a Filosofia e a Psicologia Social. A Terapia Ocupacional, nas duas últimas décadas, também passou a contribuir com essas discussões, ao buscar investigar um uso prático desse conceito ${ }^{8-12}$.

Em linhas gerais, podemos dizer que a vida cotidiana pode ser entendida como "o centro real da práxis, onde se realiza o movimento de produção e de reprodução das relações sociais, onde se dá a produção do ser humano, no curso de seu desenvolvimento histórico" (p.43) ${ }^{13}$.

Galheigo $^{12}$ discute a incorporação do conceito de cotidiano na terapia ocupacional, como superação da lógica de treinamento de atividades da vida diária e prática para a construção de sentidos do sujeito para suas atividades cotidianas, incluindo assim aspectos subjetivos, culturais, sociais, e o contexto sócio histórico em que se dá o processo terapêutico.

É no constante movimento entre individual e social, que Benetton ${ }^{9}$ sugere que a criatividade pessoal de nossos sujeitos-alvo, experimentada/construída/descoberta na relação com o terapeuta ocupacional e as atividades, possa preencher o espaço e o tempo cotidianos, no sentido de poder ser de sua posse.

Cotidiano, assim, muito mais do que um conceito "atual" para a terapia ocupacional, nos traz o desafio de, em qualquer campo de atuação, oferecer meios para que os coletivos e sujeitos-alvo de nossas intervenções possam projetar sua vida, e construir um novo sistema de valores que o possibilite ser, fazer e se relacionar a seu modo no social $^{14}$.

Assim, resgatando as reflexões de Kujawski ${ }^{15}$, o cotidiano envolve processos que possibilitam a realização de projetos pessoais, na medida em que nos familiariza com o que está em nossa volta, com as pessoas e as coisas, nos oferece alguma estabilidade e direção para projetarmos o futuro. Esses processos e a suposta segurança oferecida pelo cotidiano podem ser percebidos em momentos constitutivos da articulação funcional da vida: trabalhar, conversar, passear, comer, habitar e morar.

Compreendemos que, o morar, ação central quanto pensamos as RT, coloca-se como algo "essencial à própria vida" (p.43) ${ }^{15}$, como possibilidade de ser somente para si mesmo, sem se sujeitar tão fortemente ao que vem de fora, para usar tempo e espaço da forma como se desejar, mas que entrará em crise caso o habitar venha a se transformar em "estreita funcionalização" (p.45) $)^{15}$. Desse modo, o morar não deveria ser capturado por padrões normativos, mas sim produzir novos sentidos e contornos, particulares em cada contexto, para cada sujeito ou grupo de moradores.

Assim, discutir aspectos desse cuidado, tomando o cotidiano e sua construção como norte, é propor uma clínica que intervêm numa esfera da vida do sujeito que inclui a habitação de um território existencial e o modo como habitamos o mundo, desde seus aspectos mais singelos até os mais complexos.

Pesquisas que discutem a prática de terapia ocupacional nos SRTs ${ }^{16,17,18}$ apontam, por um lado, para a necessidade de avaliação desses serviços, para a necessidade de investigações que levem ao aprimoramento das estratégias teórico-práticas relativas a esse campo, e por outro lado, a emergência de intervenções ligadas a ampliação da autonomia, maior apropriação dos espaços da casa e do território por parte dos moradores.

Nessa direção, pretendemos contribuir com o aprimoramento dessas estratégias, discutindo a construção das ações terapêuticas ocupacionais nesses espaços tendo em vista a superação da lógica manicomial.

\section{METODOLOGIA}

As explanações sobre as RTs e as contribuições da Terapia Ocupacional nesse cenário podem ser descritas a partir de múltiplas perspectivas; no entanto neste trabalho optamos por abordá-los, considerando a dimensão da experiência, ou seja, a dimensão da clínica cotidiana que é produzida nesses serviços em correlação com as produções teóricas sobre o tema.

Em nossa perspectiva, a experiência é o que nos passa, o que nos acontece, o que nos toca; a experiência é um encontro, uma relação com algo que se experimenta, que se prova, e que, a partir dela algo se produz, se cria ${ }^{19}$.

Desse modo, a construção que aqui se apresenta se dá a partir da análise de registros realizados pelo período de um ano (novembro de 2010 - dezembro de 2011) em um diário de campo que funcionava como um caderno de comunicação entre terapeutas ocupacionais que atuaram na implementação e acompanhamento de duas Residências 
Ferigato SH, et al. As residências terapêuticas e a clínica do cotidiano. Rev Ter Ocup Univ São Paulo.2016 jan./abr.;27(1):80-7.

Terapêuticas na cidade de Campinas-SP e experimentaram alguns modos de intervir.

Cada uma das residências contava com um total de seis moradores. Essas casas eram acompanhadas pela equipe interdisciplinar de um CAPS-III, compondo a Rede de Saúde Mental da cidade.

Entre os membros que realizavam o acompanhamento da casa, contávamos com duas terapeutas ocupacionais que eram referências técnicas das Residências Terapêuticas, além de mais duas terapeutas ocupacionais que prestavam assistência terapêutica a essas casas em atendimentos semanais.

No chamado "diário de campo", eram registradas as intervenções dos terapeutas ocupacionais na casa, bem como suas percepções, constituindo-se como um espaço de nota, avaliação, comunicação e troca entre as terapeutas ocupacionais que atuavam no SRT.

Esses diários eram preenchidos com uma periodicidade semanal, onde eram registradas intervenções com sujeitos individuais, com o grupo de moradores, questões para outras terapeutas, impressões pessoais, percepções, registros dos procedimentos e técnicas de intervenção realizadas na casa. As autoras dos diários são também autoras desse texto. A instituição em que esses diários se construíram autorizou o uso dos mesmos, mas não foi identificada para preservar a identidade dos usuários e trabalhadores.

A metodologia de análise dos diários utilizada para a produção desse manuscrito se espelha na proposição diarística da Análise Institucional ${ }^{20,21}$, a partir da modalidade funcionalista de análise de diários institucionais. Segundo Lourau $^{20}$, esse modo de análise de dados se constitui a partir da fusão de três movimentos: o levantamento dos dados observados; as impressões e percepções do diarista que finalmente se entrelaçam com construções técnicas e teóricas.

O uso do diário de campo tradicionalmente se constituiu como uma ferramenta de pesquisa, mas, estudos brasileiros recentes, têm mostrado sua eficácia também como um instrumento para a gestão, para o ensino e para registro/reflexões da prática clínica ${ }^{22}$. Por esse motivo, optamos pelo uso desse método para a produção dos dados e análises que respaldam esse relato de experiência vivenciada na clínica psicossocial.

Como a construção desses diários inicialmente não se destinava a uma pesquisa acadêmica, mas sim à prática clínica, trechos do diário não se apresentam e não foram disponibilizados na composição escrita do texto, que se deu a partir das co-relações entre conceitos teóricos e a sistematização do conteúdo dos diários de campo. Essa sistematização foi feita em quatro momentos articulados: (1) Leitura dos diários de campo;(2) análise da produção dos terapeutas ocupacionais; (3) Categorização das ações dos terapeutas ocupacionais a em planos de intervenção; (4) Construção da escrita.

\section{RESULTADOS}

Com o objetivo de sistematizar as ações dos terapeutas ocupacionais que contribuem para o trabalho nas Residências Terapêuticas, identificamos quatro planos de intervenção.

\section{Intervenções na casa e no espaço de morar}

As intervenções na casa começaram desde o momento de sua escolha. Os registros das profissionais indicavam o cuidado de garantir a participação dos moradores nos processos de escolha do local do imóvel, de compra dos utensílios e móveis, bem como da organização da rotina - elementos fundamentais para a eficácia de um processo de desinstitucionalização. Essas intervenções tinham seu fundamento no estímulo à apropriação do espaço e de tudo aquilo que está contido nele, como algo que lhe pertence por direito, que foi por ele construido, e que é diferente de algo “dado", que pertence às instituições.

Outro fundamento importante era o cuidado para não institucionalizar o espaço da casa. Entendemos que uma RT não será, em nenhum momento, uma casa como outra qualquer, pela natureza que a caracterizam e a viabilizam, no entanto, também não deve se constituir como um setting de trabalho comum, como outros serviços de saúde.

Isso demanda que os trabalhadores das instituições que acompanham os moradores da casa assumam uma nova postura. Assim, tomar atitudes simples como: "bater na porta", "pedir licença”, incluir objetos de decoração construídos pelos moradores contribuíam para evitar sua institucionalização. Todos os profissionais que lá atuavam tinham recomendações de buscar evitar procedimentos técnicos tradicionais (como os realizados em instituições de saúde), bem como organizações rígidas do controle do tempo e das atividades domésticas, distanciando-se de práticas institucionalizantes dentro do "espaço de morar", que precisaria se diferenciar, o máximo possível, dos “espaços de tratar". Essa vivência está atrelada não somente a um espaço físico, mas a um lar, que se abre como potência para processos de reconstrução e atualização de novos processos de subjetivação. 
Ferigato SH, et al. As residências terapêuticas e a clínica do cotidiano. Rev Ter Ocup Univ São Paulo. 2016 jan./abr.;27(1):80-7.

As intervenções se davam com vistas à apropriação das pessoas em relação àquele espaço, pessoas que tem um lugar e que pode nele ter suas coisas, sua subjetividade.

\section{Intervenções junto aos sujeitos e grupo de moradores}

No processo de reabilitação, vivenciado a partir do cotidiano de cada morador, mais do que a conquista de novas habilidades ou inserções no mundo pragmático, verificamos a construção dos direitos substanciais de cada um, a inserção em um mundo relacional no qual se é agente ativo.

A circulação dos afetos, dos valores e a efetiva transformação ocorrida nas dinâmicas da casa e dos espaços coletivos de circulação dos moradores, são perceptíveis em cada intervenção. Neste contexto, "O compromisso reabilitacional passa a ser de fato, com o desenvolvimento da vida, no sentido de ser no social, na trama do cotidiano" (p.45) ${ }^{10}$.

Iniciando pela composição do grupo que irá habitar um mesmo SRT ressaltamos que este deve ser diferente de um mero agrupamento de pessoas. Os registros mostravam que os resultados mais positivos, se davam quando se levava em consideração a singularidade de cada morador, afinidades, escolhas e interesses em comuns, desde a seleção até a consolidação de um grupo de moradores.

Dentro do espaço da casa, era possível acompanhar os moradores em suas atividades cotidianas, buscando favorecer o diálogo entre os moradores no sentido de qualificar a convivência mútua, intermediar conflitos, construir junto aos moradores estratégias de gestão da casa e de divisão de responsabilidades domésticas, construir colaborativamente pactos que orientassem as possibilidades e os limites de cada um e do grupo.

Fora do espaço da casa, era prática do terapeuta ocupacional realizar atividades para a apropriação do território e a constituição de novos laços sociais junto à comunidade e à cidade. Essa tarefa é comum na prática da profissão e tem grandes aproximações com a prática dos Acompanhamentos Terapêuticos (AT) realizados na tradicionalmente no campo da Saúde Mental.

Essas atividades externas incluíam ensinar um morador a pegar ônibus, a realizar procedimentos bancários, compras no supermercado, a criar laços de vizinhança, se inserir em atividades do bairro. Todas essas atividades exigem o trabalho de uma série de elementos objetivos e subjetivos inerentes à própria experiência e que representam um grande desafio para parte das pessoas com transtornos mentais, especialmente aquelas que tiveram suas vidas atravessadas por longas permanências em instituições fechadas.

Estávamos diante de práticas da ordem de ações educativas, culturais, terapêuticas e sócio-inclusivas que possibilitam ao sujeito cuidar de si, conhecer sua forma de fazer as atividades e de se relacionar consigo e com o mundo.

\section{Intervenções junto ao território e comunidade}

Possibilitar a apropriação do espaço e do território como inclusão social é um elemento essencial na clínica do cotidiano, mas abarca o trabalho com estigmas, preconceitos e dificuldades para se relacionar com as pessoas com transtornos mentais. As intervenções dessa natureza se davam por meio de atividades que envolviam a circulação no espaço urbano do bairro e a realização de atividades com a comunidade em geral.

Em situações de produção de conflitos relacionais, muitas vezes era necessária à mediação por parte dos profissionais, com o cuidado de desconstruir estigmas e ao mesmo tempo não produzir práticas de infantilização dos usuários.

As atividades de circulação pelo bairro eram singulares para cada morador, a partir de suas necessidades e desejos, em um movimento que, muitas vezes, se dava por estímulo dos profissionais, vizinhos ou dos moradores, com convites para participar em eventos públicos, etc e outras vezes por necessidades próprias, como cuidados com a saúde e satisfação de vontades.

Assim, a Unidade Básica de Saúde, as igrejas, as escolas, espaços culturais e de convivência, supermercados, farmácias, açougues, padarias, salões de beleza, começavam a ser frequentados pelos moradores da casa, que levavam sua loucura para outros territórios, trazendo um novo mundo para seu cotidiano.

Buscamos entender o território, não somente como o bairro do domicilio do sujeito, mas como o conjunto de referências sociais, culturais, políticas e econômicas que desenham a moldura do cotidiano, do projeto de vida, da inserção no mundo ${ }^{23}$.

Trata-se, portanto da construção de novas respostas sociais para a loucura. A possibilidade de voltar a frequentar diferentes espaços de uma cidade, implica o retorno (ou um novo início) à cena urbana, extrapolando os ganhos pessoais de cada morador e invadindo a vida social.

Assim, intervir no território junto com os moradores das RT era uma intervenção construída nas trocas relacionais com a vizinhança, com os comerciantes locais, com o espaço urbano, operando-se, assim, a 
Ferigato SH, et al. As residências terapêuticas e a clínica do cotidiano. Rev Ter Ocup Univ São Paulo.2016 jan./abr.;27(1):80-7.

possibilidade real de transformação do imaginário e dos estigmas relacionados à loucura.

\section{Intervenções junto à equipe interdisciplinar e intersetorial}

Para a efetividade dessa construção, as terapeutas ocupacionais, em conjunto com outros profissionais, atuaram em diferentes contextos, em processos de educação permanente junto á equipe de cuidadores para lidar com o processo de reabilitação psicossocial, nas reuniões de equipe, supervisões clínico-institucionais, comissões de moradia e capacitações.

Ao atuar nas RT, os profissionais da saúde são convidados a experimentar as potências e os limites da Reforma Psiquiátrica em sua radicalidade. É possível identificar grandes transformações psicossociais desde em pequenos gestos até projetos de grande mudança, desde o compartilhar de um café até a inserção em atividades de trabalho.

Essas mudanças não poderiam se concretizar sem a parceria com profissionais de outros setores, como Assistência Social, Educação e a Cultura.

Para conquistas junto aos moradores como processos de inserção escolar e cultural, para conquista de benefícios de prestação continuada e inclusão no trabalho, essas parcerias foram fundamentais.

Isso implica em uma postura de intervenção técnica em terapia ocupacional que se integra com uma dimensão ética e política das práticas de saúde, um compromisso com a criação de novas possibilidades de convívio social para todos, com a renovação das respostas da sociedade civil, levando a uma transformação concreta da realidade, ainda que com os inúmeros desafios desse cenário.

\section{DISCUSSÃO}

Quando articulamos cada um dos possíveis planos de intervenção mencionados anteriormente, fica claro que as intervenções no âmbito individual, grupal, coletivo, ou territorial, dentro ou fora do setor saúde, caracterizam-se como ações do campo da saúde mental e não exclusivamente do núcleo da terapia ocupacional. No entanto, também fica explícito que esses diferentes planos são atravessados por um plano transversal, que é um dos principais objetos da terapia ocupacional - o plano do cotidiano: de pessoas, de grupos de usuários ou trabalhadores, do cotidiano da casa, dos processos de trabalho, da cotidianeidade do território. Cotidianos singulares e plurais que se confrontam e/ou se compõe o tempo todo.
Nesse sentido, as RTs estão longe de, em si, constituírem-se como soluções mágicas para a desistitucionalização de egressos de manicômios, pois, é em seu processo de construção, no cotidiano, na trama das relações entrelaçadas ao sabor dos acontecimentos, que as dificuldades e possibilidades se apresentam, especialmente quando nos referimos a cotidianos que precisam ser (re)construídos em termos espaciais, afetivos e socioculturais ${ }^{24}$. Em situações como essa, pudemos identificar que a terapia ocupacional pode oferecer muitas contribuições a partir das especificidades do seu núcleo, que historicamente aborda os processos de inclusão e exclusão por meio de transformações concretas na vida cotidiana de sujeitos individuais e coletivos.

Pensar planos de intervenção em SRT a partir do cotidiano, nos permite identificar no plano micropolítico do cuidado em terapia ocupacional e da atenção psicossocial, as lógicas excludentes e manicomiais que tendem a perseverar. Do mesmo modo, podemos identificar e ativar as novas maneiras de viver e pensar a relação com a loucura. Isso equivale a se pensar na "desinstitucionalização como ativação da força-invenção da vida" 25 .

\section{CONSIDERAÇÕES FINAIS}

O objetivo geral deste trabalho foi construir uma reflexão crítica sobre o papel do terapeuta ocupacional nos SRTs. Identificamos que esse processo deve necessariamente incluir o trabalho com os desafios de morar e habitar um território.

Para isso, inicialmente contextualizamos os SRT no âmbito da Reforma Psiquiátrica, situando o terapeuta ocupacional, como membro de uma equipe interdisciplinar, e a Terapia Ocupacional como um núcleo que contribui para a construção desta prática inovadora de inclusão social. Principalmente por envolver uma clínica que abre muitos espaços para que o 'novo' possa surgir, é uma clínica que ora está mais próxima da construção do cotidiano (tendo em vista a despotencialização desse processo instaurado pelo manicômio) e ora mais próxima de sua ampliação ${ }^{10}$.

A partir da análise dessa experiência, identificamos 04 planos de intervenções que os terapeutas ocupacionais podem desenvolver para o aumento da potência dos SRTs e de seus moradores: intervenções na casa, junto aos moradores, ao território e à comunidade, e junto à equipe interdisciplinar e intersetorial. Esses quatro planos são atravessados pela cotidianeidade de instituições, indíviduos, grupos, coletivos, processos de trabalho e territórios. 
Ferigato SH, et al. As residências terapêuticas e a clínica do cotidiano. Rev Ter Ocup Univ São Paulo. 2016 jan./abr.;27(1):80-7.

Consideramos que, para todo caso indicado para uma RT, é necessária a construção de uma indicação e acompanhamentos criteriosos, sempre cuidando para não reproduzir práticas manicomiais ou demasiadamente assistencialistas. Além disso, embora apostemos na eficácia destes serviços, entendemos que o processo do "morar" bem como a saída do hospital psiquiátrico não é algo simples e internalizado facilmente para estes usuários, futuros moradores das casas. Esse fator diz respeito a questões

\section{REFERÊNCIAS}

1. Yasui S. Rupturas e encontros: desafios da reforma psiquiátrica brasileira. Rio de Janeiro: Editora Fiocruz; 2010.

2. Furtado JP. Avaliação da situação atual dos serviços residenciais terapêuticos existentes no SUS. Ciênc Saúde Coletiva. 2006;11(3):785-95. http://dx.doi.org/10.1590/ S1413-81232006000300026.

3. Brasil. Ministério da Saúde. Portal da Política Nacional de Saúde Mental. Portaria n. 3.088 de 23 de dezembro de 2011. Disponível em: http://bvsms.saude.gov.br/bvs/saudelegis/ gm/2011/prt3088_23_12_2011_rep.html

4. Palladini PCN. Dois anos e meio de lar abrigado no Juqueri. Arq Saúde Ment Estado São Paulo. 1987;46:62-6.

5. Guimarães J, Saeki T. Janelas do Santa Tereza: estudo do processo de reabilitação psicossocial do Hospital Psiquiátrico de Ribeirão Preto. Hist Ciênc SaúdeManguinhos. 2001;8(2):357-74. http://dx.doi.org/10.1590/ S0104-59702001000300004.

6. Suiyamara RCB, Rolim MA, Colvero LA. Serviços residenciais terapêuticos em saúde mental: uma proposta que busca resgatar a subjetividade dos sujeitos? Saúde Soc. 2007;16(3):102-10. http://dx.doi.org/10.1590/S010412902007000300010 .

7. Brasil. Ministério da Saúde. Secretaria de Atenção à Saúde. Departamento de Ações Programáticas Estratégicas. Residências terapêuticas: o que são, para que servem. Brasília: Ministério da Saúde; 2004. Disponível em: http://bvsms.saude.gov.br/bvs/ publicacoes/120.pdf.

8. Almeida MA. Pessoa portadora de deficiência física em seu cotidiano: reflexo e reflexões sobre a reabilitação. 1993 [Dissertação]. São Paulo: Universidade de São Paulo, Instituto de Psicologia; 1993.

9. Benetton J. Encontro do sentido do cotidiano na terapia ocupacional para a construção de significados. Rev CETO. individuais e coletivas de extrema complexidade que precisam ser cotidianamente e delicadamente trabalhados, e a formação do terapeuta ocupacional é consistente nessa direção.

Buscamos apresentar algumas características consideradas relevantes para o fortalecimento e eficácia terapêutica desses serviços, na perspectiva, não de esgotar a temática, mas sim, de instigar a construção de práticas criativas em torno dessa clínica, sempre em reforma, sempre em constante movimento e criação.

2010;13(13):32-9. Disponível em: http://www.ceto.pro.br/ revistas/12/12-06.pdf.

10. Castro ED, Lima EA, Brunello MIB. Atividades humanas e Terapia ocupacional. In: Terapia Ocupacional no Brasil: fundamentos e perspectivas. São Paulo: Plexus Editora; 2001. p.41-62.

11. Francisco BR. Terapia ocupacional. 2a ed. Campinas: Papirus; 2003.

12. Galheigo SM. O Cotidiano na terapia ocupacional: cultura, subjetividade e contexto histórico-social. Rev Ter Ocup Univ São Paulo. 2003;14(3)104-109. http://dx.doi. org/10.11606/issn.2238-6149.v14i3p104-109.

13. Lima S. Participação social no cotidiano. 5a ed. São Paulo: Cortez; 1993.

14. Benetton J, Marcolino TQ. As atividades no método terapia ocupacional dinâmica. Cad Ter Ocup UFSCar. 2013;21(3):645-652. http://dx.doi.org/10.4322/cto.2013.067.

15. Kujawski GM. A crise do século XX. São Paulo: Ática; 1988.

16. Trava BU, Ballarin MLGS. Serviço residencial terapêutico: uma perspectiva frente ao processo de desinstitucionalização. Rev UNIVAP. 2006;13:235. Disponível em: http://www.inicepg.univap.br/cd/ INIC_2006/inic/inic/03/INIC0001280ok.pdf.

17. Mângia EF, Ricci EC. Pensando o habitar. Rev Ter Ocup Univ São Paulo. 2011;22(2):182-90. http://dx.doi. org/10.11606/issn.2238-6149.v22i2p182-190.

18. Mângia EF, Rosa CA. Desinstitucionalização e serviços residenciais terapêuticos. Rev Ter Ocup Univ São Paulo. 2002;13(2):71-7. http://dx.doi.org/10.11606/issn.22386149.v13i2p71-77.

19. Bondía JL. Notas sobre a experiência e o saber da experiência. Rev Bras Educ (Rio de Janeiro). 2002;19(1):19-28. 
20. Lourau R. Processamento de texto. [A do livro]. Altoé S. Rene Lourau: analista institucional em tempo integral. São Paulo: Hucitec; 2004.

21. Hess R. Momento do diário e o diário do momento. Tempos, narrativas e ficções: a invenção de si. Porto Alegre: PUCRS; 2006.

22. Pezzato LM, L'abbate S. O uso de diários como ferramenta de intervenção da análise institucional: potencializando reflexões no cotidiano da saúde bucal coletiva. Physis Rev Saúde Coletiva. 2011;21(4):1297-314. http://dx.doi. org/10.1590/S0103-73312011000400008.

23. Delgado PG, et al. Rede, Território, e Atenção Psicossocial informações demográficas e sócio-econômicas sobre as regiões atendidas pelos CAPS de campo Grande e Santa Cruz - Relatório preliminar 1. Rio de Janeiro: IFB/ IMASJM; 1997.

24. Gaudencio MMP, Silva TL, Martiniano CS. Uma delicada ponte entre o passado e o presente: percepções do cuidar elaboradas pelos moradores de Residências Terapêuticas. In: Silveira MF, Santos Junior HPO, organizadores. Residências terapêuticas: Pesquisa e Prática nos processos de desisntitucionalização. Campinas Grande: EDUEPB; 2011. Disponível em: http://books.scielo.org/id/pgwpg/12.

25. Romagnoli RC, Paulon SM, Amorim AKDMA, Dimenstein M. Por uma clínica da resistência. Interface Comunic Saúde Educ. 2009;13(30):199-207. http://www.scielo.br/pdf/icse/ v13n30/v13n30a16.pdf.

Artigo recebido em: 15.05 .15

Artigo aceito em: 30.03.16 